\title{
Pengeluaran Pemerintah dan Indeks Pembangunan Manusia (IPM) Di Provinsi Bengkulu
}

\section{Aan Zulyanto}

\begin{abstract}
Human Development Index (HDI) is one indicator to evaluate the government performance. This index is consist of several main components such as education, health, and economy. This study aims to see how the effect of government spending on education, health, and infrastructure on the Human Development Index in the province of Bengkulu. It also analyzes the differences of HDI level in main and proliferation region as a response to regional autonomy in Indonesia. This Study uses panel data for kabupaten-kota in Bengkulu province during the period 2007-2013. It uses Random Effect Model (GLS) as estimation technique, based on formal testing against several estimation techniques associated with panel data. The results are the education spending has significant positive effect on the HDI. Substantial budget allocations for education that can improve HDI in Bengkulu province. While health and infrastructure spending are not significant, but it shows a negative relationship. It indicates the inefficiency and inaccuracy targets of the health budget and infrastructure in the Bengkulu province. Meanwhile, the study also finds a significant difference in the level of HDI, where main regions have HDI levels higher than the expansions.
\end{abstract}

Keywords: Government Expenđiture, Education, Health, Infrastructure, HDI

(C2018 Universitas Prof. Dr. Hazairin, SH.

\section{Latar Belakang}

Sejak dilaksanakan otonomi daerah dan desentralisasi fiskal di Indonesia melalui UU No. 22 dan 25 tahun 1999 serta diperbaharui melalui UU 32 dan 33 Tahun 2004, pemerintah daerah memiliki peran yang semakin besar dalam pembangunan di daerah. Semangat otonomi daerah ini didasarkan pada suatu pemahaman bahwa pemerintah daerah memiliki pengetahuan yang lebih baik mengenai masalah-masalah dan kebutuhan di daerah dibandingkan dengan pemerintah pusat, sehingga dengan diberikan kewenangan yang luas terhadap pemerintah daerah untuk menyelenggarakan pemerintahan, diharapkan tujuan pembangunan ekonomi yang sasaran akhirnya adalah kesejahteraan masyarakat lokal dapat lebih cepat tercapai.

\section{Aan Zulyanto}

Fakultas Ekonomi Univ. Prof. Dr. Hazairin, SH Bengkulu

Jl. Jenderal A. Yani No. 1 Kota Bengkulu

Email : aanzulyanto@gmail.com 
United Nations Development Programe (UNDP) pada awal tahun 1990 memperkenalkan konsep Indeks Pembangunan Manusia (IPM) sebagai ukuran kuantitatif untuk mengukur kualitas sumber daya manusia. Pada dasarnya IPM adalah suatu indeks komposit yang mencakup tiga bidang pembangunan manusia yang dianggap sangat mendasar yang dilihat dari kualitas fisik dan non fisik penduduk. Adapun 3 indikator tersebut yaitu: indikator kesehatan, tingkat pendidikan, dan indikator ekonomi. Kualitas fisik tercermin dari angka harapan hidup, sedangkan kualitas non fisik tercermin dari lamanya rata-rata penduduk bersekolah dan angka melek huruf, dan mempertimbangkan kemampuan ekonomi yaitu pengeluaran riil per kapita.

Luasnya cakupan pembangunan manusia menjadikan peningkatan IPM sebagai manifestasi dari pembangunan manusia dapat ditafsirkan sebagai keberhasilan dalam meningkatkan kemampuan dalam memperluas pilihan-pilihan (enlarging the choices of the people). Seperti diketahui, beberapa faktor penting dalam pembangunan yang sangat efektif bagi pembangunan manusia adalah pendidikan dan kesehatan. Dua faktor penting ini merupakan kebutuhan dasar manusia yang perlu dimiliki agar mampu meningkatkan potensinya. Umumnya, semakin tinggi kapabilitas dasar yang dimiliki suatu bangsa, semakin tinggi pula peluang untuk meningkatkan potensi bangsa itu (BPS, 2008).

Pelajaran dari berbagai Negara memperlihatkan dua strategi utama untuk meningkatkan kualitas sumber daya manusia, antara lain melalui pemerataan distribusi pendapatan serta memberikan porsi yang lebih memadai terhadap alokasi belanja publik sektor pendidikan dan kesehatan. Korea Selatan sebagai contoh sukses, tetap konsisten melakukan dua hal tersebut. Sebaliknya Brazil mengalami kegagalan karena memiliki distribusi pendapatan yang timpang dan alokasi belanja publik yang kurang memadai untuk pendidikan dan kesehatan (BPS, 2008).

Dalam studinya mengenai Human Development Indeks, Renggo (2010) menemukan bahwa Pengeluaran Pemerintah dalam bidang Kesehatan dan Infrastruktur berpengaruh secara signifikan terhadap terhadap Human Development Index (HDI) di Provinsi Jawa Tengah. Pengeluaran pemerintah atas pendidikan, kesehatan dan infrastruktur merupakan suatu investasi terhadap Human Development Index. Hasil ini juga dinyatakan Astri, dkk (2012), bahwa pengeluaran pemerintah di bidang pendidikan berpengaruh positif secara signifikan terhadap HDI. Sementara itu, Usmaliadanti (2011) menambahkan variabel kemiskinan sebagai determinan Human Development Indeks, dan dia juga membuktikan bahwa angka kemiskian dan pendidikan berpengaruh signifikan terhadap nilai HDI. Berkaitan dengan IPM ini, Brata (2002) memberikan bukti adanya hubungan dua arah antara pembangunan manusia dan pembangunan ekonomi regional di Indonesia, termasuk di masa krisis. Pembangunan manusia yang berkualitas mendukung pembangunan ekonomi dan sebaliknya kinerja ekonomi yang baik mendukung pembangunan manusia.

Dalam konteks provinsi Bengkulu, pencapaian nilai IPM selama periode 20022010 menunjukkan trend yang semakin baik. Pada tahun 2002 nilai IPM provinsi Bengkulu sebesar 66,2 dan naik menjadi 69,9 di tahun 2004. Sampai tahun 2010 nilai IPM provinsi Bengkulu mencapai 72,92.

Secara umum, jika dibandingkan dengan nilai HDI Indonesia pada periode tersebut, terlihat bahwa nilai HDI Provinsi Bengkulu selalu lebih tinggi. Hal ini mengisyaratkan bahwa kualitas pembangunan manusia di provinsi Bengkulu secara rata-rata lebih baik dari pencapaian pembangunan Manusia yang dihasilkan secara nasional.. Meskipun 
demikian, dari tabel di atas juga terlihat bahwa keberhasilan pembangunan manusia melalui peningkatan IPM tidak begitu sejalan dengan penurunan angka kemiskinan di provinsi Bengkulu. Selama periode 2004-2013, angka kemiskinan masih menunjukkan tingkat yang tinggi dan jauh di atas rata-rata nasional. Tahun 2004 tingkat kemiskinan di Bengkulu mencapai 22,4 persen sedangkan tingkat kemiskinan Indonesia sebesar 16,7 persen. Pada tahun 2013, tingkat kemiskinan di provinsi Bengkulu turun menjadi 17,5 persen, akan tetapi masih jauh lebih tinggi dari tingkat kemiskinan Indonesia yang "hanya" sebesar 11,3 persen.

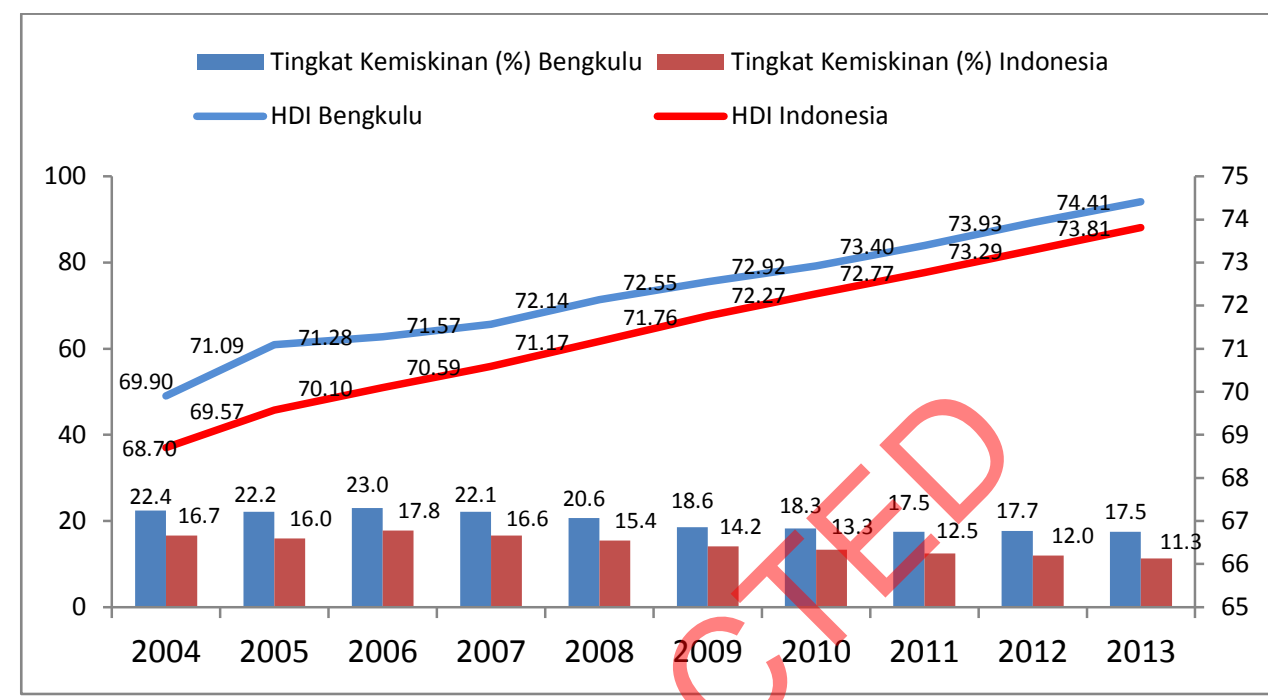

Gambar 1 : Perkembangan Indeks Pembangunan Manusia dan Tingkat Kemiskinan di Provinsi Bengkulu dan Indonesia Tahun 2004-2013

Sumber: BPS, berbagai tahun

Adanya kesenjangan yang cukup besar antara kualitas Pembangunan Manusia yang tercermin pada nilai Human Development Indeks (HDI) dengan Tingkat Kemiskinan di Provinsi Bengkulu, terutama dalam semangat otonomi daerah dan desentralisasi fiskal yang memberikan peran lebih besar pada pemerintah daerah untuk melaksanakan pembangunan, maka penulis tertarik untuk melakukan studi dengan judul "Pengeluaran Pemerintah dan Indeks Pembangunan Manusia (IPM) di Provinsi Bengkulu“.

Adapun yang menjadi rumusan masalah dalam penelitian ini adalah Bagaimana pengaruh Pengeluaran Pemerintah dalam bidang Pendidikan, Kesehatan dan Infrastruktur terhadap Indeks Pembangunan Manusia (IPM) di Provinsi Bengkulu? Serta apakah terdapat perbedaan pengaruh Pengeluaran Pemerintah dalam bidang Pendidikan, Kesehatan dan Infrastruktur terhadap Indeks Pembangunan Manusia (IPM) antara daerah induk dan pemekaran di Provinsi Bengkulu.

\section{Literatur Review}

\subsection{Indeks Pembangunan Manusia (IPM)}

Menurut UNDP (1990), pembangunan manusia merupakan model pembanguanan yang ditujukan untuk memperluas pilihan yang dapat ditumbuhkan melalui upaya pemberdayaan penduduk. Pemberdayaan penduduk ini dapat dicapai melalui upaya yang menitikberatkan pada peningkatan kemampuan dasar manusia yaitu meningkatkan 
derajat kesehatan, pengetahuan dan keterampilan agar dapat digunakan untuk mempertinggi partisipasi dalam kegiatan produktif, sosial, budaya dan politik. Upaya untuk mengangkat manusia sebagai tujuan utama pembangunan, sebenarnya telah muncul dengan lahirnya konsep "basic need development". Paradigma ini mengukur keberhasilan pembangunan dengan menggunakan Indeks Mutu Hidup (Physical Quality Life Index), yang memiliki tiga parameter, yaitu: angka kematian bayi (infant motality rate), angka harapan hidup waktu lahir (life expentancy) dan tingkat melek huruf (literacy rate). Indikator untuk mengukur keberhasilan pembangunan manusia terus dikembangkan, sehingga muncul paradigma baru pembangunan manusia yang diukur dengan Indeks Pembangunan Manusia (Human Development Index).

Dalam Human Development Report dijelaskan bahwa Indeks pembangunan Manusia (IPM) merupakan suatu konstruksi pengukuran atas dasar konsep right based approach to human development. HDI melakukan pengukuran rata-rata capaian setiap individu negara yang menyangkut tiga dimensi dasar dari proses pengembangan kualitas manusia. Pengukuran ini dilakukan dengan menetapkan beberapa asumsi dasar bahwa manusia yang berkualitas adalah: Manusia yang dapat hidup sehat dan panjang umur, Manusia yang memiliki kecakapan dan pendidikan yang diperlukan bagi hidupnya, dan Manusia yang dapat mencapai standar hidup layak.

Peningkatan status pembangunan manusia berdasarkan klasifikasi berikı

- $<50$; Rendah

- $50 \leq \mathrm{IPM}<66$; Menengah bawah

- $66 \leq \mathrm{IPM}<80$; Menengah atas

- $\geq 80$; Tinggi

Sementara Kuncoro (2003) mengajukan kalsifikasi penetapan kategori IPM didasarkan pada skala $0,0-1,0$ yang terdiri dari:

- Kategori rendah : nilai IPM 0-0,5

- Kategori menegah : nilai IPM antara 0,51-0,79

- Kategori tinggi : nilai IPM 0,8-1

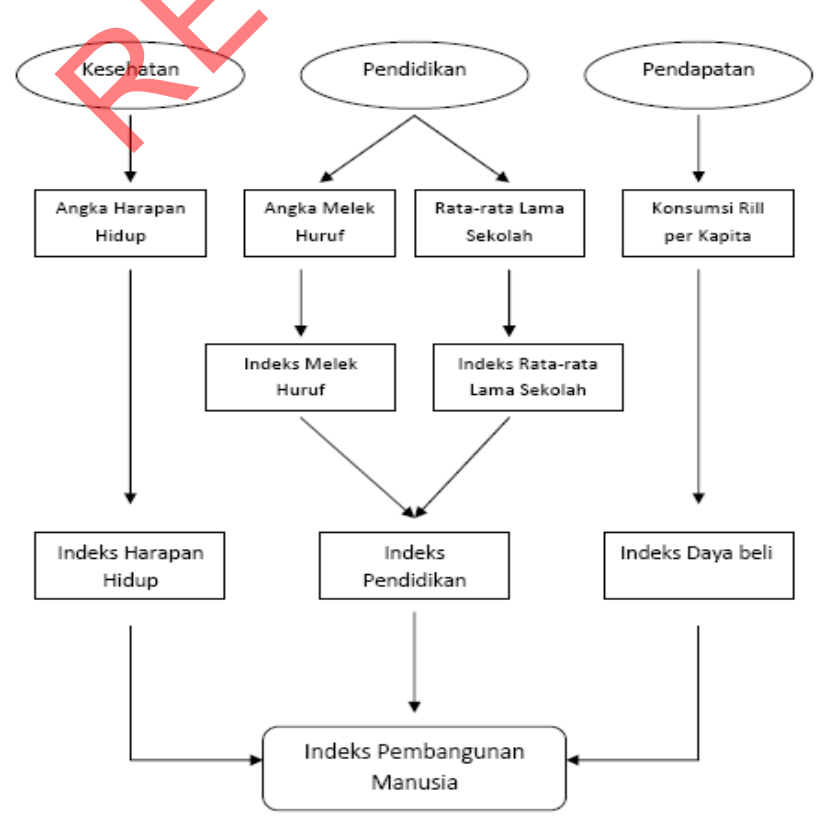

Gambar. 2 : Komponen HDI

Sumber : Maqin (2007) 


\subsection{Pengeluaran Pemerintah dalam Pembangunan}

Campur tangan pemerintah dalam perekonomian modern semakin dibutuhkan, tidak hanya berkaitan dengan adanya persoalan eksternalitas dan kegagalan system pasar dalam penyediaan barang publik, tetapi pemerintah perlu menjamin bahwa fasilitas dasar yang dibutuhkan masyarakat dapat tersedia secara memadai melalui pemanfaatan sumber daya secara maksimal. Mangkoesoebroto (1999) mengidentifikasikan tiga fungsi/peran yang dimiliki pemerintah yaitu; (i) Peranan Alokasi atau efisiensi, yaitu peranan pemerintah untuk mengusahakan agar alokasi sumber-sumber ekonomi dilaksanakan secara efisien, (ii) Peranan Distribusi, yaitu peranan pemerintah untuk mendistribusikan sumberdaya dan manfaat pembangunan agar tercipta keadilan dalam masyarakat, dan (iii) Peranan Stabilisasi, yaitu peranan pemerintah dalam menciptakan kestabilan dalam perekonomian sehingga menjamin ketenangan berusaha bagi setiap warga masyarakat. Selain ketiga peran tersebut, Dumairy (1999) menambahkan peran dinamisatif, yakni peranan pemerintah dalam menggerakkan proses pembangunan ekonomi agar lebih cepat tumbuh, berkembang dan maju.

Implementasi campur tangan pemerintah dalam perekonomian dan usaha peningkatan kesejahteraan masyarakat antara lain dilakukan melalui kebijakan anggaran yang tepat. Pengeluaran pemerintah secara mikro dimaksudkan untuk menyediakan barang publik yang tidak dapat disediakan pihak swasta sebagai akibat adanya kegagalan pasar (Nicholson, 2002). Pengeluaran/belanja pemerintah untuk barang publik akan menstimulasi pengeluaran untuk barang lain (Mangkoesoebroto, 1999).

Hall (2010) menyatakan bahwa Belanja publik merupakan faktor kunci bagi pertumbuhan dan pembangunan ekonomi. Ia sangat esensial untuk mendanai infrastruktur, termasuk jalan, listrik, dan air. Ia menyediakan layanan kesehatan dan pendidikan yang diperlukan untuk ekonomi modern dengan lebih efisien dan efektif dibandingkan yang mampu diseđiakan pasar. Belanja publik juga dimanfaatkan di seluruh dunia untuk memberikan stimulus ekonomi guna melawan resesi, dan menyelamatkan bank-bank melalui kepemilikan publik. Lebih lanjut dijelaskan bahwa Belanja publik adalah cara yang lebih efisien untuk memproduksi banyak layanan. Studi baru baru ini terhadap belanja kesehatan dan pendidikan di negara-negara OECD menemukan bahwa belanja publik lebih memengaruhi pertumbuhan GDP daripada belanja yang dikeluarkan swasta. Ini konsisten dengan bukti-bukti nyata bahwa belanja publik pada kesehatan jauh lebih efisien, dalam batas-batas ekonomi, dan lebih efektif, dalam batas-batas tujuan penyediaan layanan kesehatan, dibandingkan belanja pihak swasta pada layanan kesehatan. Haryanto dkk (2005) menunjukkan bahwa persentase pengeluaran pemerintah untuk kesehatan berpengaruh secara signifikan terhadap tingkat kematian balita. Secara umum ditunjukkan bahwa peningkatan pengeluaran pemerintah untuk sektor kesehatan terbukti cukup besar memberikan peningkatan kinerja sektor tersebut.

Peranan pemerintah dalam dunia pendidikan tidak hanya mencerminkan masalah kepentingan pemerintah tetapi juga aspek ekonomi yang dimiliki oleh sektor pendidikan, karena pada dasarnya pendidikan merupakan sebuah investasi. Menurut teori human capital, pendidikan merupakan faktor yang dominan untuk menghasilkan masyarakat berproduktivitas tinggi. Teori ini percaya bahwa investasi dalam pendidikan merupakan investasi untuk meningkatkan produktivitas masyarakat. Oleh sebab itu pemerintah harus dapat membangun suatu sarana dan sistem pendidikan yang baik (Achsanah dalam Amanda, 2010). Menurut Friawan (2008), implikasi dari 
pembangunan dalam pendidikan adalah kehidupan manusia akan semakin berkualitas. Semakin tinggi kualitas hidup suatu bangsa, semakin tinggi tingkat pertumbuhan dan kesejahteraan bangsa tersebut. Semakin tinggi kualitas hidup / investasi sumber daya manusia akan berimplikasi terhadap tingkat pertumbuhan ekonomi nasional.

Selain anggaran pendidikan dan kesehatan, alokasi anggaran Infrastruktur juga memiliki peran penting dalam pembangunan suatu negara. Pembangunan Infrastruktur menunjukkan seberapa besar pemerataan pembangunan ekonomi terjadi. Suatu negara dengan pertumbuhan ekonomi tinggi akan mampu melakukan pemerataan pembangunan kemudian melakukan pembangunan infrastruktur keseluruh bagian wilayahnya. Perekonomian yang terintegrasi membutuhkan pembangunan infrastruktur. Setidaknya ada tiga alasan utama mengapa infrastruktur penting dalam sebuah integrasi ekonomi (Friawan, 2008) ;. Pertama, ketersedian infrastruktur yang baik merupakan mesin utama pemacu pertumbuhan ekonomi, misalnya studi The World bank (2004) menyatakan bahwa tingkat pertumbuhan ekonomi yang rendah dalam beberapa tahun terakhir pasca krisis ekonomi 1998 salah satunya dipengaruhi rendahnya tingkat investasi. Kurangnya ketersediaan infrastruktur merupakan salah satu hambatan utama dalam perbaikan iklim investasi di Indonesia. Kedua, untuk memperoleh manfaat yang penuh dari integrasi, ketersediaan jaringan infrastruktur sangat penting dalam memperlancar aktifitas perdagangan dan investasi. Ketiga, perhatian terhadap perbaikan infrastruktur juga penting untuk mengatasi kesenjangan pembangunan ekonomi.

Dalam konteks empiris, beberapa studi terdahulu telah menemukan keterkaitan antara alokasi anggaran tersebut terhadap indeks pembangunan manusia. Maryani (2011) mendapatkan bahwa pendidikan, kesehatan, dan jumlah penduduk miskin berpengaruh positif terhadap IPM. Astri (2012) yang menyimpulkan bahwa anggaran pendidikan berpengaruh terhadap IPM, namun anggaran kesehatan tidak terbukti berpengaruh. Mendukung Astri, Usmaliadanti (2011) jumlah penduduk miskin, pengeluaran Pendidikan berpengaruh signifikan terhadap variabel pembangunan manusia, pengeluaran kesehatan tidak berpengaruh Secara signifikan. Sebaliknya Renggo (2011) mendapatkan bahwa pengeluaran kesehatan dan infrastruktur berpengaruh meningkatkan HDI indonesia dan signifikan. Sedangkan pengaruh pengeluaran pendidikan tidak signifikan. Brata (2002) PDRB dan pendidikan terbukti sangat signifikan Pengaruhnya terhadap IPM. Widodo, dkk (2011) menggunakan IPM sebagai variable moderating atas pengaruh pengeluaran pendidikan dan kesehatan terhadap tingkat kemiskinan. Begitu juga Suliswanto (2010) mendapatkan IMP berpengaruh negative signifikan terhadap tingkat kemiskinan.

\section{Data dan Methode Analisis}

Studi menggunakan data sekunder meliputi data IPM kabupaten/kota di provinsi Bengkulu, Anggaran Pendapatan dan Belanja Daerah (APBD), Tingkat Kemiskinan, PDRB serta data-data relevan lainnya. Sumber data diperoleh dari Biro Pusat Statistik (BPS), Dinas Pendapatan Daerah, Bank Indonesia Bengkulu, serta instansi terkait lainnya. Selain itu sumber data juga diperoleh dari akses melalui internet dengan situs antara lain; www.djpk.depkeu.go.id, www.bi.go.id, www.bps.go.id dan www.bpk.go.id.

Jenis data adalah data unbalanced panel, meliputi 10 daerah kabupaten/kota di provinsi Bengkulu yaitu Kota Bengkulu, Bengkulu Utara, Bengkulu Selatan, Rejang 
Lebong, Seluma, Kaur, Lebong, Kepahiang, Kabupaten Muko-Muko, dan Kabupaten Bengkulu Tengah dalam periode 2007-2013. Data bersifat unbalanced dikarenakan salah satu daerah (kabupaten Bengkulu tengah) baru terbentuk tahun 2008, sehingga data yang tersedia mulai tahun 2009 .

Studi ini mengelaborasi berbagai penelitian sebelumnya, terutama yang dilakukan Renggo (2010) dan Usmaliadanti (2011), serta menambahkan kajian pada daerah Induk dan pemekaran sebagai salah satu konsekuensi pelaksanaan otonomi daerah dan desentralisasi fiskal di Indonesia.

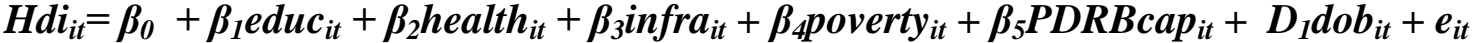

Dimana HDI adalah angka Human Development Indeks atau Indeks Pembangunan Manusia, sementara educ, health, dan Infra masing-masing merupakan persentase Pengeluaran Pendidikan, kesehatan, dan infrastruktur terhadap total belanja daerah. Selanjutnya juga digunakan dua variabel kontrol yaitu tingkat kemiskinan (poverty) dan PDRB perkapita. Kedua variabel ini dimasukan kedalam model karena dalam studi sebelumnya, kedua variable ini terbukti signifikan dalam mempengaruhi Indek Pembangunan Manusia (IPM). Meskipun demikian, beberapa studi menemukan hubungan sebaliknya antara tingkat kemiskinan dan indeks pembangunan manusia, seperti Widodo dkk (2011) dan Suliswanto (2010), oleh sebab itu akan dilakukan uji kausalitas granger untuk melihat apakah terdapat hubungan saling mempengaruhi antara kedua variable tersebut.

Dalam studi menggunakan data panel, setidaknya terdapat tiga tehnik analisis yang dapat digunakan yaitu Pooled Regression atau OLS biasa, Fixed Effect Model, dan Random Effect Model atau GLS (Gujarat dan Porter, 2012, Greene, 2012). Pilihan untuk menggunakan tehnik estimasi sangat tergantung pada asumsi terhadap Unobserved Heterogenity atau individual specific $\left(\mathrm{a}_{\mathrm{i}}\right)$ yang ada dalam model data panel. Secara sederhana, model data panel dapat dibuat sebagai berikut:

$$
\mathrm{y}_{\mathrm{it}}=\beta_{1} \mathrm{x}_{\mathrm{it} \hat{Y}}+\ldots+\beta_{\mathrm{k}} \mathrm{x}_{\mathrm{itk}} \mathrm{a}_{\mathrm{i}}+\mathrm{u}_{\mathrm{it}}, \mathrm{t}=1,2, \ldots \mathrm{T}
$$

Dimana $\mathrm{a}_{\mathrm{i}}$ merupakan unobserved heterogenity atau Individual Specific yaitu semua yang tidak terobservasi (time-constant factor) yang dapat mempengaruhi y. Model Pooled Regression tidak memperlihatkan dimensi individu maupun waktu. Diasumsikan bahwa perilaku data sama dalam berbagai kurun waktu. Ini adalah teknik yang paling sederhana untuk mengestimasi data panel.

Metode Fixed Effect (FEM) mengasumsikan bahwa Unobserved Heterogenity $\left(a_{i}\right)$ berkorelasi dengan $\mathrm{x}_{\mathrm{i}}$. FEM mengasumsikan slope konstan tetapi intersep berbeda antara individu, menempatkan bahwa $\mathrm{u}_{\mathrm{it}}$ merupakan kelompok spesifik atau berbeda dalam constant term pada model regresi. Pengertian fixed effect ini didasarkan adanya perbedaan intersep antara daerah namun intersepnya sama antar waktu (time invariant). FEM sesuai untuk situasi dimana individual-specific intersep berkorelasi dengan satu atau lebih regressor. FEM dapat diestimasi menggunakan Least Square Dummy Variable (LSDV) maupun Within Transformation Estimator. Salah satu kerugian LSDV adalah kehilangan banyak degree of freedom ketika jumlah cross section (daerah) sangat besar. Formulasi FEM dengan metode Within Transformation.

$$
\begin{aligned}
& \mathrm{y}_{\mathrm{it}}-\overline{\mathrm{y}}_{\mathrm{i}}=\beta_{1}\left(\mathrm{x}_{\mathrm{it} 1}-\overline{\mathrm{x}}_{\mathrm{i}}\right)+\ldots+\beta_{\mathrm{k}}\left(\mathrm{x}_{\mathrm{itk}}-\overline{\mathrm{x}}_{\mathrm{i}}\right)+\left(\mathrm{u}_{\mathrm{it}}-\overline{\mathrm{u}}_{\mathrm{i}}\right), \mathrm{t}=1,2, \ldots \mathrm{T} \\
& \text { atau } \ddot{\mathrm{y}}=\beta_{1} \ddot{\mathrm{x}}_{\mathrm{it} 1}+\ldots+\beta_{\mathrm{k}} \ddot{\mathrm{x}}_{\mathrm{itk}}+\ddot{\mathrm{u}}_{\mathrm{it}} \text {, } \\
& \text { dimana } \ddot{y}=y_{i t}-\bar{y}_{i}
\end{aligned}
$$


Selanjutnya Model Random Effect mengasumsikan Unobserved Heterogenity $\left(a_{i}\right)$ merupakan faktor yang acak $\left(E\left(a_{i} \mid x\right)=0, \operatorname{cov}\left(X, a_{i}\right)=0\right.$, tetapi komposit error $\left(a_{i}+\right.$ $\mathrm{e}_{\mathrm{it}}$ ) akan terdapat serial korelasi. Dalam konteks ini OLS tidak dapat digunakan. Random Efek merupakan model pertengahan antara FEM dan OLS, dengan formulasi sebagai berikut:

$$
\mathrm{y}_{\mathrm{it}}-\lambda \overline{\mathrm{y}}_{\mathrm{it}}=\beta_{0}(1-\lambda)+\beta_{1}\left(\mathrm{x}_{\mathrm{it}}-\lambda \overline{\mathrm{x}}_{\mathrm{i}}\right)+\ldots+\beta_{\mathrm{k}}\left(\mathrm{x}_{\mathrm{itk}}-\lambda \overline{\mathrm{x}}_{\mathrm{itk}}\right)+\left(\mathrm{e}_{\mathrm{it}}-\lambda \overline{\mathrm{e}}_{\mathrm{i}}\right)
$$

Dimana $\lambda$ merupakan faction dari y rata-rata $\left(\bar{y}_{\mathrm{it}}\right)$. Jika $\lambda=1$, maka estimasi mendekati FEM, dan bila $\lambda=0$, estimasi mendekati OLS, dengan formulasi sebagai berikut (Wooldridge, 2009)

$$
\lambda=1-\left[\sigma_{u}^{2} /\left(\sigma_{u}^{2}+T \sigma_{a}^{2}\right)\right]^{1 / 2},
$$

Untuk memilih model yang tepat, Widarjono (2007) menyarankan beberapa uji yang perlu dilakukan, yaitu. Uji Signifikansi Fixed Effect (Uji F), yaitu untuk mengetahui apakah teknik regresi data panel dengan fixed effect lebih baik dari model regresi data panel tanpa variabel dummy atau OLS, dan Uji Hausman yang bertujuan untuk memilih apakah menggunakan model fixed effect atau random effect yang paling baik untuk digunakan. Uji Hausman ini didasarkan pada ide bahwa LSDV di dalam metode fixed effect dan GLS adalah efisien sedangkan metode OLS tidak efisien, di lain pihak alternatifnya metode OLS efisien dan GLS tidak efisien. Karena itu uji hipotesis nulnya adalah hasil estimasi keduanya tidak berbeda sehingga sehingga uji Hausman bisa dilakukan berdasarkan perbedaan estimasi tersebut.

Selanjutnya dilakukan juga pengujian beberapa asumsi klasik yang relevan, khsusunya normalitas dan multikolineritas. Sementara untuk autokorelasi dan heterokedastisitas telah diakomodir dalam penggunaan data panel.

\section{Hasil Penelitian}

\subsection{Hasil Pengujian Model dan test Statistik}

Hasil pengujian model secara formal untuk memilih tehnik estimasi yang sesuai memperlihatkan bahwa model Random Efek (GLS) merupakan tehnik estimasi yang paling sesuai dengan studi. Pengujian pertama menggunakan $\mathrm{F}$ test, untuk memilih antara Common Effect (OLS) dan Fixed effect, dimana hasil $\mathrm{F}$ test menunjukkan bahwa model Fixed efek lebih sesuai dibandingkan dengan model OLS. Sementara pengujian kedua, antara Fixed effect dengan random efek melalui Hausman Test menghasilkan bahwa model Random effect merupakan pilihan terbaik dalam estimasi, dengan demikian hasilnya akan digunakan untuk pembahasan utama studi ini. Berdasarkan hasil hausman test ini, maka tehnik analisis yang digunakan dalam penelitian ini adalah Random effect model (GLS). Model GLS ini juga memungkinkan penggunaan variabel Dummy untuk mengidentifikasi perbedaan tingkat HDI antara daerah Induk dan pemekaran, sementara jika digunakan pendekatan Fixed Effect Model, maka perbandingan daerah induk dan pemekaran tidak dapat dilakukan dengan menggunakan variabel dummy, sehingga harus dilakukan dengan analisis uji beda, seperti independent sample $\mathrm{t}-$ test. 
Tabel 1. Fixed Effect Test

\begin{tabular}{|lrrr|}
\hline $\begin{array}{l}\text { Redundant Fixed Effects Tests } \\
\text { Equation: Untitled } \\
\text { Test cross-section fixed effects }\end{array}$ & & & \\
\hline \hline Effects Test & Statistic & d.f. & Prob. \\
\hline \hline Cross-section F & 196.225259 & $(9,36)$ & 0.0000 \\
Cross-section Chi-square & 195.657433 & 9 & 0.0000 \\
\hline
\end{tabular}

Sumber : Hasil pengolahan data, Eviews

HO; Common Pool, H1: Fixed Effect

Tabel 2. Hausman Test

Correlated Random Effects - Hausman Test

Equation: Untitled

Test cross-section random effects

\begin{tabular}{lrrr} 
& Chi-Sq. & Chi-Sq. & Prob. \\
$\begin{array}{l}\text { Test Summary } \\
\begin{array}{l}\text { Cross-section } \\
\text { random }\end{array}\end{array}$ & Statistic & d.f. & \\
\hline
\end{tabular}

Sumber : Hasil pengolahan data, Eviews

HO ; Random Effect H1: Fixed Effect

Hasil uji asumsi normalitas juga memperlihatkan nilai Jaque Berra sebesar 3.799 dan probabilitas sebesar 0.149, sehingga data bersifat normal. Begitu juga hasil korelasi parsial antar variable bebas, menunjukkan tidak ada korelasi yang sangat kuat antar variable, dengan demikian model terhindarkan dari persoalan multikolinearitas.

Untuk melihat potensi adanya hubungan kausalitas dua arah antara IPM dengan kemiskinan digunakan uji kausalitâs granger.

Tabel 3. Uji Granger IPM dan Kemiskinan

\begin{tabular}{|llll|}
\hline $\begin{array}{l}\text { Pairwise Granger Causality Tests } \\
\text { Date: 05/04/16 Time: 20:36 } \\
\text { Sample: } 20072013 \\
\text { Lags: } 1\end{array}$ & & \\
\hline \hline & & & \\
Null Hypothesis: & Obs & $\begin{array}{c}\text { F- } \\
\text { Statistic }\end{array}$ & Prob. \\
\hline \hline $\begin{array}{l}\text { POVERTY does not Granger Cause HDI } \\
\text { HDI does not }\end{array}$ & & 0.41628 & 0.5215 \\
Granger Cause POVERTY & & 15.7363 & 0.0002 \\
\hline
\end{tabular}

Sumber : Hasil pengolahan data, Eviews 
Hasil granger menunjukkan terdapat kausalitas searah, dimana hanya tingkat kemiskinan yang terbukti signifikan mempengaruhi IPM, sementara pengaruh sebaliknya yaitu IPM terhadap kemiskinan tidak terbukti signiifkan. Berdasarkan kausalitas granger ini, maka kita dapat memasukan variable kemiskinan terhadap menjadi salah satu variable control dalam melihat pengaruh pengeluaran pemerintah terhadap IMP

\section{Koefisien Determinasi $\left(\boldsymbol{R}^{2}\right)$, Uji t (parsial), dan Uji F (simultan)}

Tabel 4 . Hasil Regresi Pengaruh Pengeluaran Pemerintah terhadap IPM di Provinsi Bengkulu

Dependent Variable: HDI

Method: Panel EGLS (Cross-section random effects)

Date: 04/25/16 Time: 21:37

Sample: 20072013

Periods included: 7

Cross-sections included: 10

Total panel (unbalanced) observations: 68

Swamy and Arora estimator of component yariances

\begin{tabular}{|c|c|c|c|c|}
\hline & $\begin{array}{r}\text { Coefficie } \\
n t\end{array}$ & Std. Error & t-Statistic & Prob. \\
\hline $\mathrm{C}$ & 72.10135 & 2.909214 & 24.78379 & 0.0000 \\
\hline EDUC & 0.076630 & 0.018809 & 4.074192 & 0.0001 \\
\hline HEALTH & & 0.056349 & -0.389834 & 0.6980 \\
\hline$|\Gamma|$ & 12612 & 0.023317 & -0.540903 & 0.5905 \\
\hline POVERT & 0.108100 & 0.036034 & -2.999945 & 0.0039 \\
\hline PDRB & 0.103444 & 0.085657 & -1.207654 & 0.2318 \\
\hline DOB & 3.433761 & 1.605478 & 2.138778 & 0.0365 \\
\hline \multicolumn{5}{|c|}{ Weighted Statistics } \\
\hline R-squared & 0.486493 & \multirow{5}{*}{\multicolumn{2}{|c|}{$\begin{array}{l}\text { Mean dependent var } \\
\text { S.D. dependent var } \\
\text { Sum squared resid } \\
\text { Durbin-Watson stat }\end{array}$}} & 9.670574 \\
\hline Adjusted R-squared & 0.435984 & & & 1.190205 \\
\hline S.E. of regression & 0.850657 & & & 44.14070 \\
\hline F-statistic & 9.631824 & & & 1.111425 \\
\hline Prob(F-statistic) & 0.000000 & & & \\
\hline
\end{tabular}

Sumber : Hasil pengolahan data, Eviews

Berdasarkan hasil penelitian diperoleh nilai koefisien Determinasi $\left(\mathrm{R}^{2}\right)$ sebesar 0,486, artinya secara keseluruhan, semua variable bebas dalam model memberikan kontribusi sebesar 48,6 persen terhadap perubahan yang terjadi pada IPM. Dengan 
demikian, model yang digunakan cukup baik untuk memprediksi perubahan IPM di provinsi Bengkulu. Hasil F hitung sebesar 9.63 dan probabilitas 0.000 sehingga secara bersama-sama semua variable bebas terbukti signifikan dalam mempengaruhi IPM. Hasil uji t (parsial) memperlihatkan bahwa variable pendidikan (educ) dan tingkat kemiskinan (poverty) terbukti signifikan memperngaruhi IPM. Pengeluaran pendidikan berpengaruh positif terhadap IPM, artinya semakin besar persentase anggaran pendidikan maka semakin tinggi tingkat IPM. tingkat kemiskinan berpengaruh negative terhadap tingkat IPM, dimana semakin tinggi tingkat kemiskinan, maka akan semakin rendah tingkat IPM daerah. Dari hasil regresi juga terlihat bahwa pengeluaran kesehatan, infrastruktur, dan PDRB perkapita tidak terbukti signifikan dalam mempengaruhi IPM di provinsi Bengkulu.

\subsection{Pengaruh Pengeluaran Pemerintah terhadap IPM di Provinsi Bengkulu.}

Dari hasil penelitian terbukti bahwa variabel pengeluaran pendidikan berpengaruh positif secara signifikan terhadap perkembangan HDI di Provinsi Bengkulu. Hasil ini sesuai dengan penelitian yang dilakukan oleh Astri (2012), Tri Maryani (2011), dan Usmaliadanti (2011) yang telah mengidentifikasi secara empiris bahwa semakin besar alokasi dan proporsi pengeluaran pendidikan akan mampu meningkatkan nilai IPM, sebaliknya pengurangan proporsi belanja pendidikan akan menurunkan angka IPM. Dengan demikian, kebijakan pemerintah yang memberi perhatian besar terhadap sektor pendidikan dengan mengamanatkan setidaknya 20 persen anggaran harus dialokasikan untuk sektor pendidikan merupakan langkah yang sangat sesuai dalam rangka meningkatkan kualitas sumber daya manusia Indonesia. Hasil studi ini juga membantah studi Renggo (2011) yang tidak dapat membuktikan pengaruh signifikan pengeluaran pendidikan terhadap IPM.

Sementara itu, hasil studi juga mendapatkan adanya pengaruh negative pengeluaran kesehatan dan infrastruktur terhadap IPM di Provinsi Bengkulu, namun pengaruhnya tidak signifikan. Hasil studi ini sejalan dengan Badrudin (2011) yang juga menemukan bahwa belanja infrastruktur di Provinsi DI Yogyakarta ternyata berhubungan negative terhadap IPM meski tidak terbukti signifikan. Hasil ini tentu perlu mendapat perhatian serius, mengingat secara konseptual seharusnya anggaran kesehatan dan infrastruktur dapat meningkatkan kualitas pembangunan manusia yang tercermin dalam IPM. Seyogyanya proporsi yang tinggi terhadap pengeluaran kesehatan dan infrastruktur, seharusnya dapat meningkatkan nilai IPM. Pengeluaran untuk bidang kesehatan diharapkan mampu meningkatkan angka harapan hidup maupun menurunkan angka kematian ibu hamil dan bayi sebagai salah satu komponen dalam penentuan pembangunan manusia (Sahrah, 2007). Sementara anggaran dalam bidang infrastruktur diharapkan mampu meningkatkan akses masyarakat dalam bidang ekonomi sehingga akan terjadi efisiensi dan pada gilirannya akan meningkatkan konsumsi riil per kapita (Delavallade dalam Badrudin, 2011). Hubungan positif signifikan anggaran kesehatan dan infrasturktur terhadap IPM dapat dilihat dalam studi Renggo (2011) dan Tri Maryani (2011) yang mendapatkan hubungan positif signifikan. Sementara hasil studi Astri (2012) dan Usmaliadanti (2011) tetap menunjukkan arah positif bagi pengaruh pengeluaran kesehatan terhadap HDI walaupun tidak signifikan.

Beberapa argumentasi yang dapat disampaikan terkait hasil yang sangat berbeda ini antara lain adalah bahwa alokasi anggaran yang besar memerlukan pemanfaatannya secara efisien dan efektif. Jika terjadi inefisiensi yang tinggi dan tidak efektif, maka

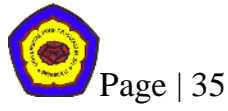


sangat dimungkinkan peningkatan anggaran justru berpengaruh negative terhadap nilai HDI, karena anggaran yang tidak efisiensi ini dapat didistribusikan kepada bidang lain yang mungkin lebih memerlukan dan bermanfaat bagi masyarakat luas. Sebagaimana hasil Kajian Pengeluaran Publik Indonesia untuk Sektor Kesehatan oleh World Bank (2008) yang menyatakan bahwa meskipun terdapat peningkatan yang substansial dalam pengeluaran publik untuk sektor kesehatan dalam beberapa tahun terakhir, secara keseluruhan pengeluaran sektor kesehatan di Indonesia masih rendah, belum merata antar dan di dalam provinsi, dan berbagai analisis juga menunjukkan adanya banyak inefisiensi.

Argument lain yang muncul terhadap fenomena ini adalah kemungkinan adanya hubungan non linear. Dalam penelitan tentang desentralisasi fiskal di Provinsi Bengkulu, Zulyanto (2012) menemukan bentuk hump-shaped pada pengaruh desentralisasi fiskal terhadap pertumbuhan ekonomi di provinsi Bengkulu, sebagaimana juga ditemukan oleh Thiessen (2003) pada desentralisasi fiskal Negara-negara OECD dan Akai, dkk (2007) pada 50 Negara Bagian USA periode 1992-1998. Bentuk Humpshaped ini mengindikasikan bahwa pada saat derajat desentralisasi fiskal rendah, peningkatan anggaran akan mendorong pertumbuhan ekonomi yang tinggi, tetapi ketika derajat desentralisasi fiskal sudah tinggi, peningkatannya justru berpengaruh negative terhadap pertumbuhan ekonomi. Berdasarkan referensi ini, jika alokasi dan proporsi anggaran yang disediakan untuk pelayanan kesehatan dan infrastuktur sudah terlampau tinggi, peningkatannya justru akan menurunkan nilai HDI di provinsi Bengkulu. Meskipun demikian, jika dibandingkan dengan anggaran yang dialokasikan untuk sektor pendidikan, rata-rata anggaran untuk sektor kesehatan dan infrastruktur masih jauh lebih rendah, sehingga argumentasi hubungan negative akibat proporsi anggaran yang tinggi dapat diabaikan. Selain itu, hasil test formal untuk melihat hubungan non linear ini juga tidak mendukung hubungan tersebut. Dengan demikian, faktor inefisiensi dan ketidaktepatan sasaran dalam implementasi anggaran kesehatan dan infrastruktur diduga menjadi penyebab dari belum mampunya dukungan anggaran kedua sektor tersebut dalam meningkatkan IPM di Provinsi Bengkulu.

Berkaitan dengan variabel kemiskinan, hasil studi menunjukkan bahwa tingkat kemiskinan berpengaruh negative secara signifikan terhadap HDI di provinsi Bengkulu. Artinya meningkatnya persentase penduduk miskin akan menyebabkan nilai HDI di provinsi Bengkulu mengalami penurunan, dan sebaliknya jika tingkat kemiskinan turun akan menyebabkan nilai HDI meningkat. Dengan demikian, berbagai kebijakan yang dilakukan pemerintah, baik pusat, provinsi, maupun kabupaten/kota untuk mengurangi kemiskinan akan berdampak signifikan bagi membaiknya nilai HDI di provinsi Bengkulu. Hasil ini sejalan dengan penelitian-penelitian sebelumnya, antara lain Suliswanto (2010), Usmaliadanti (2011), dan Tri Maryani (2011). Sementara itu variable PDRB perkapita tidak terbukti siginikan dalam mempengaruhi IPM di provinsi Bengkulu. Hasil ini berbeda dengan temuan Brata (2002) yang secara tegas mendapatkan pengaruh positif signifikan PDRB terhadap IPM.

\subsection{Perbedaan IPM antara daerah Induk dan Pemekaran di Provinsi Bengkulu.}

Perbedaan nilai IPM antara daerah induk dan pemekaran diidentifikasi melalui penggunaan variabel dummy yang diintegrasikan ke dalam model. Hasil studi menunjukkan bahwa terdapat perbedaan yang sangat signifikan antara tingkat IPM di daerah induk dan daerah pemekaran, dimana daerah induk memiliki tingkat IPM yang lebih tinggi. Hal ini sejalan juga dengan dekskripsi data yang terdapat pada uraian 
sebelumnya, dimana rata-rata nilai IPM daerah Induk, yaitu kabupaten Bengkulu Selatan, Bengkulu Utara, Rejang Lebong, dan Kota Bengkulu dinyatakan lebih tinggi dibanding daerah pemekaran. Hasil ini juga sejalan dengan hasil studi (Bappenas dan UNDP, 2008) yang mengidentifikasikan bahwa daerah otonom baru ternyata tidak berada dalam kondisi awal yang lebih baik dibandingkan daerah induk atau daerah kontrol. Bahkan evaluasi setelah lima tahun perjalanannya, daerah otonom baru secara umum masih tertinggal. Dari aspek kinerja perekonomian daerah ditemukan dua masalah utama yang dapat diidentifikasi yaitu: pembagian potensi ekonomi yang tidak merata, dan beban penduduk miskin yang lebih tinggi.

Di provinsi Bengkulu, sebagian besar daerah pemekaran umumnya merupakan daerah yang belum begitu berkembang, minim fasilitas dan infrastuktur publik, juga rendahnya kualitas fasilitas sosial ekonomi dan kesehatan, sehingga hal ini berimplikasi terhadap rendahya nilai IPM yang akan dicapai oleh daerah pemekaran. Disisi lain, daerah pemekaran sebagian besar masih memiliki ketergantungan yang tinggi terhadap sumber penerimaan dari pemerintah pusat, dan pada saat bersamaan potensi lokal daerah belum sepenuhnya terkelola dengan baik karena keterbatasan berbagai hal termasuk infrastuktur dan sumber daya lainnya. Tingginya ketergantungan fiskal ini, menyebabkan daerah tidak memiliki keleluasaan fiskal (fiscal discretions) untuk membangun daerah. Ketergantungan fiscal ini mengindikasikan belum efektifnya kebijakan keuangan daerah dalam menggerakkan aktifitas ekonomi di daerah baik yang bersifat konsumtif maupun investasi (Bappenas dan UNDP, 2008)

\section{Simpulan dan Saran}

Anggaran pendidikan berpengaruh positif secara signifikan terhadap Indeks Pembangunan Manusia (IPM) dî provinsí Bengkulu. Dengan demikian peningkatan alokasi belanja untuk pendidikan dapat mendorong kualitas sumber daya manusia yang tercermin pada peningkatan IPM, Sementara itu, anggaran Kesehatan dan Infrastruktur memiliki pengaruh negative, namun secara statistik tidak signifikan. Faktor inefisiensi dan ketidaktepatan sasaran diduga menjadi salah satu penyebab munculnya pengaruh negative terhadap pengeluaran kesehatan dan infrastuktur ini, Alokasi belanja yang besar tanpa disertai efisiensi tidak memberikan hasil pembangunan yang berkualitas, sehingga lebih baik anggaran didistribusikan kepada sektor publik yang lebih efisien. Perlu ada kajian terhadap efisiensi dan proporsi anggaran kesehatan dan infrastruktur karena berpotensi menurunkan nilai IPM.

Tingkat Kemiskinan berpengaruh negative secara signifikan terhadap nilai IPM di provinsi Bengkulu. Pengaruh negative tingkat kemiskinan ini sejalan dengan penelitianpenelitian sebelumnya, dimana penurunan angka kemiskinan dapat mendorong peningkatan nilai IPM. Pemerintah harus mampu menekan tingkat kemiskinan di provinsi Bengkulu, karena penurunan tingkat kemiskinan, apalagi bila dibandingkan sacara nasional, tingkat kemiskin Bengkulu tergolong sangat tinggi.

Adanya perbedaan signifikan IPM antara daerah induk dan daerah pemekaran, dimana daerah Induk umumnya memiliki IPM yang lebih tinggi Pembagian potensi ekonomi yang tidak merata dan beban tanggungan penduduk miskin yang tinggi menjadi faktor penting bagi perbedaan ini. Selain itu, ketergantungan fiskal yang tinggi terhadap sumber dana pusat menyebabkan daerah pemekaran masih terbatas dalam melakukan pembangunan di daerah.

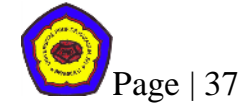




\section{DAFTAR PUSTAKA}

Akai, Nobuo, Yukihiro Nishimura, Masayo Sakata, 2007. Complementarity, Fiscal Decentralization and Economic Growth, Economics of Governance. Heidelberg: Sep 2007. Vol. 8, Iss. 4; p. 339

Amanda, Rica. 2010. Analisis Efisiensi Teknis Bidang Pendidikan Dalam Implementasi Model Kota Layak (studi kasus 14 kabupaten/kota di provinsi jawa tengah tahun 2008). Skripsi. Universitas Diponegoro.

Astri, Meylina, 2012. Pengaruh Pengeluaran Pemerintah Daerah Pada Sektor Pendidikan Dan Kesehatan Terhadap Indeks Pembangunan Manusia Di Indonesia, Jurnal Pendidikan Ekonomi dan Bisnis, Vol.1 No. 1 Tahun 2012

Badrudin, Rudi, 2011. Pengaruh Pendapatan dan Belanja Daerah Terhadap Pembangunan Manusia di Provinsi Daerah istimewa yogyakarta, BULETIN EKONOMI, Jurnal Manajemen, Akuntansi, dan Ekonomi Pembangunan, Volume 9, Nomor 1, April 2011, Fakultas Ekonomi Universitas Pembangunan Nasional "Veteran" Yogyakarta.

Bappenas \& UNDP, 2008. Studi Evaluasi Dampak Pemekaran Daerah 2001-2007, Penerbit, Brigde (Building and Reinveting decentralized Government), Jakarta.

Bappenas. 2002. Kebijakan dan Strategi Penanggulangan Kemiskinan Perkotaan: Sebuah Gagasan. Bappenas. Jakarta.

BPS, 2008. Indeks Pembangunan Manusia 2006-2007.

Brata, Aloysius Gunadi, 2002. Pembangunan manusia Dan kinerja ekonomi regional di Indonesia, Jurnal Ekonomi Pembangunan Kajian Ekonomi Negara Berkembang, Vol 7, No. 2, 2002

Dumairy 1999, Perekonomian Indonesia, Erlangga, Jakarta

Friawan, Deni. 2008, Kondisi Pembangunan Infrastruktur di Indonesia. CSIS Vol.37. No.2 Juni 2008. Jakarta: Lembaga Penerbit Fakultas Ekonomi Universitas Indonesia.

Greene, William H, 2012. Econometric Analysis : $7^{\text {th }}$, Pearson, Prentice Hall.

Gujarati N Damodar dan Porter Dwan C, 2009. Basic Econometrics, Fifth Edition, The McGraw-Hill Companies.

Hall, David, 2010. Mengapa Kita Membutuhkan Belanja Public, PSIRU, University of Greenwich

Haryanto Tri, Unggul H dan Achmad Solihin. 2005. Pengeluaran Pemerintah dan Kinerja Sektor Pendidikan serta Kesehatan di Jawa Timur. Majalah Ekonomi, Tahun XIV No.2, 2 Agustus 2005, Fakultas Ekonomi Universitas Airlangga.

Kuncoro, Mudrajad. 2003. Ekonomi Pembangunan: Teori, Masalah, dan Kebijakan Edisi Ketiga. UPP AMP YKPN. Yogyakarta.

Kuncoro, Mudrajat. 2004. Otonomi dan Pembangunan Daerah : Reformasi, Perencanaan, Strategi, dan Peluang, Jakarta, Erlangga.

Mangkoesoebroto, Guritno. 1999. Ekonomi Publik. BPFE. Yogyakarta.

Maqin, Abdul, 2007. Indeks Pembangunan Manusia: Tinjauan Teoritis Dan Empiris Di Jawa Barat, Makalah Disampaikan pada acara Pelatihan Program Pendanaan Kompetsi Indeks pembangunan Manusia (PPK-IPM) Kab. Sumedang, tanggal 31 Mei 2007.

Nicholson ,Walter .2002. Mikroekonomi Intermediate dan Aplikasinya : Edisi Delapan.Jakarta: Erlangga 
Renggo, Yuniarti Reny, 2011. Pengaruh Pengeluaran Pemerintah Dalam Bidang Pendidikan, Kesehatan dan Infrastruktur terhadap Human Development Index (HDI), Tesis, program magister sains \& doctor Ilmu ekonomi-manajemenakuntansi Fakultas ekonomika dan bisnis UGM.

Sahrah, Alimartus. 2007. Memberdayakan Sumber Daya Manusia Untuk Meningkatkan Kualitas Bangsa. Pidato Dies Natalis Unwama ke XXI, Yogyakarta.

Suliswanto, Muhammad Sri Wahyudi, 2010. Pengaruh Produk Domestik Bruto (PDB) Dan Indeks Pembangunan Manusia (IPM) Terhadap Angka Kemiskinan Di Indonesia, Jurnal Ekonomi Pembangunan, Vol 8 No. 2 Desember 2010.

Sumodiningrat, G, 1999. Ekonometrika; Pengantar, Yogyakarta, BPFE.

Thiessen, Ulrict, 2003. Fiscal Decentralization and Economic Growth in High Income OECD Countries, Fiscal Studies Vol. 24 No. 3

Tri Maryani, 2011. Analisis Indeks Pembangunan Manusia Di Provinsi Jawa Tengah, thesis, UPN "Veteran" Yogyakarta.

UNDP, 1990. Human Development Report.

Usmaliadanti, Christina, 2011. Analisis Pengaruh Tingkat Kemiskinan, Pengeluaran Pemerintah Sekor Pendidikan Dan Kesehatan Terhadap Indeks Pembangunan Manusia Di Provinsi Jawa Tengah Tahun 2007-2009, Skripsi, FE UNDIP.

Widarjono, A, 2007. Ekonometrika; Teori dan Aplikasi untuk Ekonomi dan Bisnis $\left(2^{\text {nd }}\right.$ edition), Yogyakarta, Ekonisia.

Widodo, Adi dkk. 2011. Analisis pengaruh pengeluaran pemerintah Di sektor Pendidikan dan Kesehatan Terhadap Pengentasan Kemiskinan Melalui Peningkatan Pembangunan Manusia di Provinsi Jawa Tengah. Jurnal Dinamika Ekonomi Pembangunan, Juli 2011, Volume 1, Nomor 1.

Wooldrige. JM, 2009, Introductory Econometrics: A Modern Approach, $4^{\text {th }}$ edition, South-Western Cengage Learning

World Bank, 2008. Kajian Pengeluaran Publik Indonesia untuk Sektor Kesehatan 2008 : Berinvestasi dalam Sektor Kesehatan Indonesia: Tantangan dan Peluang untuk Pengeluaran Publik di Masa Depan, Jakarta.

Zulyanto, Aan, 2012. Pengaruh Desentralisasi Fiskal Terhadap Pertumbuhan Ekonomi di Provinsi Bengkulu, Jurnal Ilmiah Ekonomi dan Pembangunan : Ecosains, Volume 1 Nomor 1 Mei 2012, Fakultas Ekonomi Universitas Negeri Padang. 


\section{Lampiran}

Hasil Regresi Model Fixed Effect

Dependent Variable: HDI

Method: Panel EGLS (Cross-section weights)

Date: 05/07/16 Time: 13:25

Sample: 20072013

Periods included: 7

Cross-sections included: 10

Total panel (unbalanced) observations: 68

Linear estimation after one-step weighting matrix

\begin{tabular}{|c|c|c|c|c|}
\hline & $\begin{array}{r}\text { Coefficie } \\
n t\end{array}$ & Std. Error & t-Statistic & Prob. \\
\hline $\mathrm{C}$ & 74.96642 & 2.633586 & 28.46553 & 0.0000 \\
\hline EDUC & 0.071919 & 0.016327 & 4.404877 & 0.0001 \\
\hline HEALTH & 0.050652 & & 1.081527 & 0.2844 \\
\hline INFRA & 0.004120 & & -0.190563 & 0.8496 \\
\hline POVERTY & 0.12 & 0.033766 & -3.715273 & 0.0005 \\
\hline PDRB & 0.134712 & 0.086969 & -1.548963 & 0.1273 \\
\hline \multicolumn{5}{|c|}{ Cross-section fixed (dummy, variables) } \\
\hline \multicolumn{5}{|c|}{ Weighted Statistics } \\
\hline R-squared & 0.914791 & \multirow{5}{*}{\multicolumn{2}{|c|}{$\begin{array}{l}\text { Mean dependent var } \\
\text { S.D. dependent var } \\
\text { Sum squared resid } \\
\text { Durbin-Watson stat }\end{array}$}} & 76.90036 \\
\hline Adjusted R-squared & 0.892283 & & & 18.31363 \\
\hline S.E. of regression & 0.866406 & & & 39.78492 \\
\hline F-statistic & 40.64295 & & & 1.150605 \\
\hline Prob(F-statistic) & 0.000000 & & & \\
\hline \multicolumn{5}{|c|}{ "Unweighted Statistics } \\
\hline R-squared & 0.925192 & \multirow{2}{*}{\multicolumn{2}{|c|}{$\begin{array}{l}\text { Mean dependent var } \\
\text { Durbin-Watson stat }\end{array}$}} & 70.69485 \\
\hline Sum squared resid & 41.29172 & & & 1.261242 \\
\hline
\end{tabular}


Hasil Regresi Model Common Effect (OLS)

Dependent Variable: HDI

Method: Panel Least Squares

Date: 05/07/16 Time: 13:24

Sample: 20072013

Periods included: 7

Cross-sections included: 10

Total panel (unbalanced) observations: 68

\begin{tabular}{|c|c|c|c|c|}
\hline & $\begin{array}{r}\text { Coefficie } \\
n t\end{array}$ & Std. Error & $\mathrm{t}$-Statistic & Prob. \\
\hline $\mathrm{C}$ & 74.03618 & 3.688789 & 20.07059 & 0.0000 \\
\hline EDUC & 0.091142 & 0.033058 & 2.756993 & 0.0077 \\
\hline HEALTH & $0.220368^{-}$ & 0.083873 & 7398 & 0.0109 \\
\hline INFRA & 0.015570 & 0.0 & & 0.6678 \\
\hline POVERTY & 0.071381 & & 016102 & 0.0482 \\
\hline PDRB & 0.148372 & 0.126846 & -1.169700 & 0.2467 \\
\hline DOB & 3.783488 & 0.656497 & 5.763143 & 0.0000 \\
\hline R-squared & 0.637372 & \multicolumn{2}{|c|}{ Mean dependent var } & 70.69485 \\
\hline Adjusted R-squ & 0.601703 & \multicolumn{2}{|c|}{ S.D. dependent var } & 2.870250 \\
\hline S.E. of regressi & 1.811437 & \multicolumn{2}{|c|}{ Akaike info criterion } & 4.123366 \\
\hline Sum squared 1 & 2001595 & \multicolumn{2}{|c|}{ Schwarz criterion } & 4.351845 \\
\hline Log likelihoo & 133.1944 & \multirow{2}{*}{\multicolumn{2}{|c|}{$\begin{array}{l}\text { Hannan-Quinn criter. } \\
\text { Durbin-Watson stat }\end{array}$}} & 4.213896 \\
\hline F-statistic & 17.86938 & & & 0.398449 \\
\hline Prob(F-statistic) & 0.000000 & & & \\
\hline
\end{tabular}


Aan Zulyanto, Pengeluaran Pemerintah Dan Indeks Pembangunan Manusia (IPM) Di Provinsi Bengkulu

Normalitas

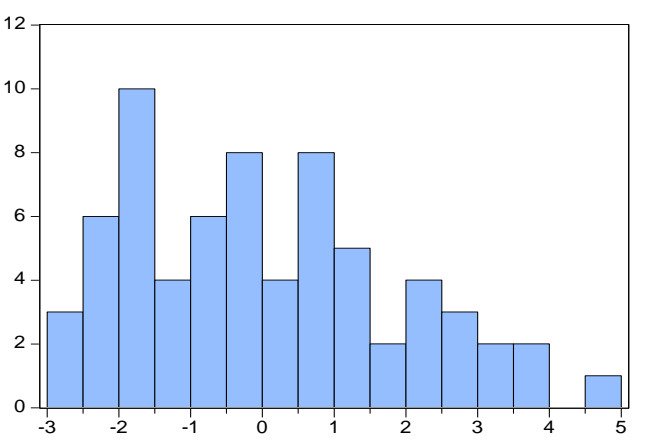

Series: Standardized Residuals

Sample 20072013

Observations 68

Mean $\quad 0.033753$

Median $\quad-0.264928$

Maximum 4.629237

Minimum $\quad-2.959147$

Std. Dev. $\quad 1.845876$

Skewness $\quad 0.511889$

Kurtosis $\quad 2.458659$

Jarque-Bera 3.799992

Probability 0.149569

Korelasi antar variable bebas

\begin{tabular}{|c|c|c|c|c|c|}
\hline & health & educ & infra & poverty & $p d r b$ \\
\hline health & 1 & 0.080 & -0.247 & 0.162 & 0.059 \\
\hline educ & 0.080 & 1 & -0.317 & 0.064 & -0.382 \\
\hline infra & -0.247 & -0.317 & 1 & -0.035 & 0.270 \\
\hline poverty & 0.162 & 0.064 & -0.035 & 1 & -0.108 \\
\hline pdrb & 0.059 & -0.382 & 0.270 & -0.108 & 1 \\
\hline
\end{tabular}

